\title{
Original article \\ Validation of the instrument "Body image after breast cancer" in Brazil
}

\author{
Carolina de Oliveira Gonçalves \\ Maria da Consolação Gomes Cunha Fernandes Tavares \\ Angela Nogueira Neves Betanho Campana \\ César Cabello \\ University of Campinas, Brazil
}

\begin{abstract}
The body image is an important aspect to be considered during the treatment of women with breast cancer. Therefore, we understand the importance of the quality of an instrument that evaluates this condition. The instrument validated in this study can bring new possibilities of studying the effects of cancer treatments on body image. Validation of the questionnaire, translation, cultural adaptation and pre-tests were done with women with breast cancer residents of the States of Alagoas, Pernambuco and São Paulo. A Confirmatory Factor Analysis (CFA) demonstrated that the original model of the instrument is valid, reliable and can be an important tool for identifying the impact of breast cancer on body image of women with this health condition, allowing adjustments in clinical treatment, psychological support and actions of other professionals involved in the treatment.
\end{abstract}

Keywords: body image, breast cancer, questionnaire, instrument validation

Resumo - "Validação do instrumento 'imagem corporal após câncer de mama' no Brasil.” A imagem corporal é um importante componente a ser considerado durante o tratamento do câncer de mama em mulheres, o que reforça a importância de um instrumento de qualidade para avaliar esta condição. $O$ instrumento validado neste estudo pode trazer novas possibilidades de estudar os efeitos de tratamentos de câncer de mama na imagem corporal. Na validação do questionário, tradução, adaptação cultural do instrumento e pré-testes foram realizados com mulheres com câncer de mama residentes nos Estados de Alagoas, Pernambuco e São Paulo. A análise estatística nos mostra que o instrumento é válido, confiável e uma ferramenta importante na identificação do impacto do câncer de mama na imagem corporal, permitindo ajustes nas condutas de tratamento clínico, apoio psicológico e na ação de outros profissionais envolvidos no tratamento.

Palavras-chave: imagem corporal, câncer de mama, questionário, validação de instrumento

Resumen - “La validación de lo instrumento 'imagen corporal después del cáncer de mama' en Brasil." La imagen corporal es un componente importante a considerar en el tratamiento de cáncer de mama en las mujeres, lo que refuerza la importancia de un instrumento de calidad para evaluar esta condición. El instrumento validado en este estudio puede aportar nuevas posibilidades para estudiar los efectos de los tratamientos para el cáncer de mama en la imagen corporal. Validación del cuestionario, traducción, adaptación cultural del instrumento y los pre-testes se llevaron a cabo con las mujeres con cáncer de mama que viven en los Estados de Alagoas, Pernambuco y Sao Paulo. El análisis estadístico muestra que el instrumento es válido, confiable y una herramienta importante para identificar el impacto del cáncer de mama en la imagen corporal, lo que permite ajustes en el tratamiento clínico, conductas de apoyo psicológico y de la acción de otros profesionales que participan en el tratamiento.

Palabras clave: imagen corporal, cáncer de mama, cuestionario, validación del instrumento

\section{Introduction}

Body image can be deeply impacted by psychological and physical factors which can cause damage to the self-identity of a person. Especially for oncological patients, changes caused by both, the diagnosis of cancer and its treatment can affect these women functionally and emotionally — most of the time in an irreversible manner (Annunziata, Giovannini, \& Muzzatti, 2012; White \& Hood, 2011). Changes in appearance and body functions, such as scars, hair loss, rashes, amputation of the breast, fatigue, and impact on sexuality are some of the elements that affect the per- ception individuals have of themselves. Secondary dysfunction in a woman's sexual life can be caused specifically by three factors: the decrease of self-esteem, impaired reproductive ability, and the side effects caused by the treatment and /or surgery (APA, 1994; Baron et al., 2000; Luskin, Warner, \& Knapik, 2006; Vamos, 1993).

In oncology, body image must be studied in a multi-dimensional way. Specifically for women with breast cancer, doctors and researchers have to understand the meaning of the breast in a patient's life, their concerns regarding appearance and body functions, their beliefs, feelings, behaviors and life experiences, rather than just a diagnosis at the end of a treatment (White \& Hood, 2011). 
Body image is considered an important component in the quality of life in patients with breast cancer (Hopwood, Fletcher, Lee, \& Al Ghazal, 2001). Cash and Pruzinsky (2002) consider that the investigation of body image is associated with quality of life, and researchers must take into account particular effects of a disease or specific treatments on body image. Another issue to consider is that studies on quality of life often associate the assessment of body image to sexuality. Although sexuality is related to body identity, it cannot be forgotten as each type of cancer is associated with specific body image concerns, and sexuality will not always be the principal focus. This situation does not allow a researcher to say that for each patient body image representation is preserved as before the diagnosis (Cash \& Pruzinsky, 2002; Hopwood et al., 2001; White, 2002).

Psycho-oncology research works on these issues in order to develop specific instruments for assessing body image in cancer patients. For women with breast cancer, the following questionnaires are available: (a) The Body Image and Relationship Scale, developed by Hormes et al. (2008); (b) The Sexual Adjustment Scale developed by Dalton et al. (2009); (c) The Body Image Scale, created by Hopwood et al. (2001); and (d) The Body Image after Breast Cancer Questionnaire, created by Baxter et al. (2006). The last one, the "Body Image after Breast Cancer Questionnaire” (BIBCQ; Baxter et al., 2006) is the focus of our research, because it meets the multidimensional perspective required in the research of oncology psychosocial features. Being multidimensional, the BIBCQ has six different factors (or dimensions): vulnerability (V), transparency (T), body stigma (BS), arm concerns (AC), body concerns (BC) and limitations (L). Therefore, the scale was designed to cover different aspects of the body image in an oncologic perspective, and allows us to monitor the long-term impact of breast cancer in women. The instrument is founded in theoretical basis with direct information about the target population, and also is grounded on earlier information in literature about body image in people with chronic diseases (Baxter et al., 2006).

In Brazil, breast cancer accounts for $22 \%$ of new cancer cases each year, with a very high mortality rate, due to its diagnosis in advanced stages. Women who survive undergo aggressive treatment and suffer with procedures that changes appearance and body functions (INCA, 2011). The literature on breast cancer in Brazil indicates that the diagnosis of breast cancer is followed by anguish, suffering, and anxiety throughout the treatment, financial insecurity caused by the cost of drugs, surgery, hospitalization, depression and a decrease in self-esteem (Venancio, 2004). The high incidence of the illness and the disruption diagnosis and treatment of breast cancer (during and at the end of the protocols) cause enormous impact in women's lives. Emphasis on understanding these changes caused by treatments would help planning interventions that may improve survival rate after cancer remission. Therefore, a specific instrument to evaluate body image after breast cancer would give researchers and doctors some relevant information about their patients' psychological health and wellbeing, and the impact of any intervention.

Base on these arguments, the purpose of this study is to investigate and cross-culturally adapt the psychometric properties of the Body Image after Breast Cancer Questionnaire (Baxter et al., 2006) to Brazil's Portuguese language. This tool will safely assess the impact of treatment and intervention programs to support women with breast cancer. Around in the world, research on breast cancer provides its contribution to possibilities of cross-cultural influences. Recently, a study from the Western University of England has investigated the psychosocial impact of breast cancer in South Asian and Black women (Patel, 2013). The study assessed the body image through the "Body Image after Breast Cancer Questionnaire" and the results have shown that the experiences due to breast cancer diagnosis and treatment can be influenced by different ethnicities/cultures. The author also has investigated women with no proficiency in English and in need of assistance of translators due to the absence of a validated questionnaire in the language of the target group. This study reinforces the importance of cross-cultural studies, and specially the validation of the questionnaires in different languages.

\section{Methods}

\section{Participants}

The sample is comprised of a non-probabilistic selection of 393 women, who attended treatment centers in several cities in the Southeastern and Northeastern region of Brazil. Patients' average age was 54.6 years $(S D=12.01)$, and they were diagnosed at 65.20 months $(S D=62.62)$. Most of the women reported being sexually active (59\%), 59\% were married, $15.4 \%$ single, $13.3 \%$ widowed, and $12 \%$ divorced. Most women $(93.2 \%)$ have only one breast affected by cancer. A mastectomy with reconstruction surgery was the most frequent procedure $(55 \%)$, followed by lumpectomy. In order to avoid research bias, the study did not include illiterate women or women who were undergoing chemotherapy during the data collection period. We believe that women undergoing chemotherapy could experience mental confusion, and illiterate women could misinterpret the questions if somebody read the questionnaire for them.

\section{Instruments}

The instrument Body Image after Breast Cancer Questionnaire - BIBCQ (Baxter et al., 2006), is a multidimensional scale designed to assess the impact of breast cancer on body image. In the original study, the questionnaire was answered by women who were treated at the University of Toronto Hospital, Ontario, Canada. The questionnaire has 45 general items, two optional items for women who have removed one or both breasts, and six items for women who did not remove either breast.

The BIBCQ questionnaire consists of six scales: (1) one scale of vulnerability (V), which assesses the sense of vulnerability of the body to other diseases and cancers; (2) a scale for body stigma (BS), which assesses the need to hide the body; (3) a scale of limitations (L), which assesses feelings of competence and skills; (4) a scale of concerns with the body (BC), which assesses satisfaction with appearance and shape of the body; (5) a scale of transparency $(\mathrm{T})$, which assesses concerns with the changes (ob- 
viously cancer-related) in appearance, and (6), a scale of concerns with the arm (AC), which assesses the worries with symptoms related to the arm and its appearance (Baxter et al., 2006, p.222).

Questions 1 to 28 include an agreement scale of 5 points (1 $=$ strongly disagree and $5=$ strongly agree). Questions 29 to 53 use a frequency scale of 5 points $(1=$ never to $5=$ always $)$. In the demographic questionnaire, participants report their age, marital status, sexual activity, and their perceptions about quality of sexual life, as well as their perceptions about financial security. These two variables include the following crude measures: (1) "Evaluate your sexual activity in the last 30 days from 0 to 10 " $(0=$ extremely poor to $10=$ very satisfactory), and (2) "How financially secure have you felt for the last 30 days"? (1= unsure to $4=$ safe $)$.

\section{BIBCQ cross-cultural adaptation}

The Portuguese version of the BIBCQ questionnaire was based on the studies of Beaton, Bombardier, Guillemin and Ferraz (2002) and Ferreira, Campana, Campana and Tavares (2011). First, the scale was translated into Portuguese by two native Brazilian individuals who were fluent in English. The translators worked independently of each other, producing two different translations (T1 and T2). A simplified version (T12) was produced by the agreement of the two translators coordinated by a neutral judge. Later, two independent translators (BT1 and BT2) translated the questionnaire back into English, resulting in a simplified version (T12). Both translators were native English speakers, but fluent in Portuguese. The complete material (T1, T2, T12, BT1 and BT2) was submitted to a committee of experts that included an oncologist, a physical therapist who was trained in psychoanalysis, a methodologist, a linguist and a member of the target population of this study. The committee prepared the pre-test version with a scale that observed semantic, idiomatic, conceptual and cultural aspects. This version was assessed by six participants for clarity of the items and their instructions, the alternatives for responses, and the layout. Situations for misunderstandings were identified in the instructions, and items 7, 11 and 32 (semantic aspects), and also in the layout. Revision of statements was discussed with the members of the committee of experts, and then, nine participants were interviewed. All critical issues were resolved, except item 7 . This item was revised by members of the committee of experts and a new simplified version was proposed. In the third pre-test, all of the items were understood by the participants regarding instructions and response options. The layout was approved as well. After this process, the Brazilian version of BIBCQ was ready for data collection.

\section{Procedures}

Prior data collection, this study was approved by the Ethics Committee of the University of Campinas (date of approval: June 22, 2010; approval number: 503/2010), as well as by each ethics committee of each participating hospital/clinic. Participants were invited from cancer treatment centers of several cities of Northeastern and Southeastern States in Brazil. The same researcher collected all the data for this study. The researcher personally invited patients to participate in the research, and explained its purpose.
Both the Consent and Awareness form and the BIBCQ questionnaire had to be read and answered by the patient, without the help of others. The time to complete the questionnaire varied greatly among participants, according to their educational level. The women who attended elementary school took an average of 30 minutes to respond the questionnaire and form. Those with high school or college degree took in average 10 minutes to fill out the questionnaire. Participation in the research was non-paid.

\section{Statistical analysis}

The Unweight Least Square (ULS) extraction method (LISREL program) was employed after detection of non-normal distribution of the data. This method allowed us to evaluate the structure factor using confirmatory factor analysis (CFA), construction validity and internal reliability of the BIBCQ Brazilian version. Items 2, 6, 8, 10, 11, 12, 14, 16, 20, 23, 24, 25, 26, 27 , 28, 37, 43 e 49, all exhibited reversed scores.

Model adjustment was assessed by multiple indicators: Goodness-of-Fit Index (GFI), Adjusted Goodness-of-Fit Index (AGFI), Normed Fit Index (NFI), Non-normed Fit Index (NNFI), and Comparative Fit Index (CFI). According to the literature (Hu \& Bentler, 1999), these indexes are expected to be equal or above 0.95. The Root Mean Square Error of Approximation (RMSEA) was also considered with acceptance values below 0.08 . In the present study, ideal values for standardized Chi-square should be smaller than 5 (Maruyama, 1998). Initial models with poor adjustment, factorial loadings, residual items, and LISREL modification rates were submitted to further adjustments. Based on Dr. Baxter recommendations, 45 common items were submitted to analysis. Items 24 and 51 were specific to women with mastectomy, without reconstruction; and items 25, 26, 27, 28, 52 and 53 were specific to women who did not undergo surgery, or had a lumpectomy, or a mastectomy performed with reconstruction. Due to specificity of these items, their inclusion on the CFA would generate an awkward matrix. After adjusting the general model, we used Spearman correlation to evaluate those items that could be in the scale that uses the total-item score correlation, and that was considered statistically relevant for correlations above 0.30 (Nunally, 1978).

To establish the internal consistency, Cronbach's alpha and construction reliability (Hair Jr. et al. 2005) were calculated. Reliability of the construction (RC) was calculated as follow:

$$
R C=\frac{\left(\sum \lambda \mathrm{j}\right)^{2}}{\left(\sum \lambda \mathrm{j}\right)^{2}+\sum \mathrm{E}_{\mathrm{j}}}
$$

Where $\lambda_{j}$ is the standardized factor load (assertion) of the $j$ indicator, and $E_{\mathrm{j}}$ is the measurement error of the $j$ indicator, calculated as 1 - reliability of the indicator. Values greater than or equal to 0.70 were accepted.

To establish the convergent validity, $t$-values and factorial loads of the observable variables were analyzed. Item factorial loads greater than 0.50 were desired, however, due to our sample size, values of 0.30 were accepted (Hair et al., 2005). T-values higher than or equal to 1.96 were considered acceptable (Garver \& Mentzer, 1999). 


\section{Hypotheses}

As part of the construction validation using a nomological network approach, we hypothesized that:

1) Considering the demographics of the sample, the BIBCQ factor related to body concerns would be associated with sexual life (Preston, 2010; White, 2000; 2002).

2) Compared to the rest of the sample with lower levels of sexual activity, the BIBCQ would differentiate groups according to their sexual activity (APA, 1994).

Table 1. Adjustment values in the BIBCQ questionnaire scale.

\begin{tabular}{|c|c|c|c|}
\hline 1. I try to hide my body (Tento esconder meu corpo). & .55 & .30 & 28.12 \\
\hline 3. I avoid looking at my scars from the breast surgery (Evito olhar minhas cicatrizes da mama). & .61 & .37 & 30.80 \\
\hline 4. I feel like there is a time bomb inside me (Sinto que há uma bomba relógio dentro de mim). & .45 & .21 & 22.35 \\
\hline 6. I am happy with my level of energy (Estou feliz com minha disposição). & .46 & .21 & 22.35 \\
\hline 8. I am satisfied with the shape of my body (Estou satisfeita com a forma do meu corpo). & .75 & .57 & 32.25 \\
\hline 9. I fell less feminine since cancer (Sinto-me menos feminina desde o câncer). & .59 & .35 & 30.06 \\
\hline 10. I like my body (Gosto do meu corpo). & .78 & .61 & 33.23 \\
\hline $\begin{array}{l}\text { 11. I feel comfortable about the way I look when I exercise (Sinto-me confortável com a minha aparência com a } \\
\text { prática da atividade física). }\end{array}$ & .65 & .47 & 29.08 \\
\hline $\begin{array}{l}\text { 12. I would feel comfortable changing in a public locker room (Sinto-me confortável trocando de roupa em um } \\
\text { vestiário público). }\end{array}$ & .52 & .27 & 25.84 \\
\hline 13. I feel my body has been invaded (Sinto que meu corpo foi invadido). & .47 & .22 & 25.11 \\
\hline 14. I am satisfied with my arm's appearance of (Estou satisfeita com a aparência do meu braço). & .73 & .54 & 21.91 \\
\hline 15. I feel like my body let me down (Sinto que meu corpo me desapontou, me deixou na mão). & .67 & .44 & 33.03 \\
\hline 16. I like my looks just the way they are (Gosto de minha aparência exatamente como ela é). & .69 & .47 & 30.31 \\
\hline 18. I feel that part of me must remain hidden (Sinto que aquela parte minha deve permanecer escondida). & .67 & .44 & 33.29 \\
\hline 19. I am afraid to touch the scars from my breast surgery (Tenho medo de tocar minhas cicarizes da cirurgia da mama). & .55 & .28 & 27.45 \\
\hline 20. I am satisfied with the appearance of my hips (Estou satisfeita com a aparência do meu quadril). & .56 & .32 & 24.68 \\
\hline 22. I feel like something is taking over my body (Sinto que alguma coisa está tomando conta do meu corpo). & .61 & .37 & 30.75 \\
\hline 23. I am satisfied with the shape of my buttocks (Estou satisfeita com a forma do meu bumbum). & .51 & .26 & 22.41 \\
\hline 29. I feel that people are looking at my chest (Sinto que as pessoas ficam olhando o meu peito). & .50 & .25 & 22.69 \\
\hline $\begin{array}{l}\text { 30. I avoid physical intimacy, such as close contact with someone (Evito intimidade física, contato muito próximo } \\
\text { com alguém). }\end{array}$ & .66 & .44 & 33.29 \\
\hline 31. I feel that people are looking at me (Sinto que as pessoas ficam me olhando). & .56 & .31 & 24.78 \\
\hline 32. I hide my body when changing clothes (Evito expor meu corpo ao trocar de roupa). & .57 & .33 & 38.49 \\
\hline $\begin{array}{l}\text { 34. I need to be reassured about the appearance of my breasts (Preciso ser tranquilizada a respeito da aparência das } \\
\text { minhas mamas). }\end{array}$ & .72 & .52 & 31.70 \\
\hline 36. Being tired interferes with my life (Estar cansada interfere na minha vida). & .64 & .41 & 28.72 \\
\hline 38. The swelling in my arm is a problem for me (O inchaço do meu braço é um problema para mim). & .48 & .23 & 17.23 \\
\hline 39. I worry about my body (Preocupo-me com meu corpo). & .53 & .28 & 31.97 \\
\hline 40. I keep my chest covered during sexual intimacy (Manteria meu peito coberto durante intimidade sexual). & .63 & .40 & 31.97 \\
\hline 41. I feel angry with my body (Sinto raiva do meu corpo). & .57 & .32 & 29.35 \\
\hline 42. I need reassurence about my health (Preciso ser tranquilizada a respeito da minha saúde). & .55 & .30 & 27.48 \\
\hline 43. I can participate in normal activities (Posso participar de atividades normais). & .52 & .27 & 24.64 \\
\hline 44. I have problems concentrating (Tenho problemas em me concentrar). & .44 & .19 & 21.54 \\
\hline 45. My body stops me from doing things I want to do (Meu corpo me impede de fazer coisas que eu gostaria de fazer). & .62 & .39 & 28.37 \\
\hline 46. I think my breasts appear uneven to others (Acho que minhas mamas parecem desiguais para os outros). & .70 & .49 & 30.85 \\
\hline 47. Arm pain is a problem for me (As dores no braço são um problema para mim). & .69 & .47 & 20.65 \\
\hline 48. I worry about minor aches and pains (Preocupo-me com pequenas dores). & .44 & .19 & 22.63 \\
\hline 49. I feel normal (Sinto-me normal). & .69 & .48 & 30.25 \\
\hline $\begin{array}{l}\text { 50. I feel that people can tell my breasts are not normal (Sinto que as pessoas podem fa } \\
\text { são normais). }\end{array}$ & .64 & .41 & 29.01 \\
\hline
\end{tabular}

$*$ Normed Chi-square: 2.48 ; RMSEA=.062; NFI=.95; NNFI= .98; CFI= .98; GFI= .96; AGFI=.96 
3) The BIBCQ would differentiate groups according to their financial security perceptions (Lam \& Fielding, 2003, Stanton \& Snider, 1993).

\section{Results}

\section{BIBCQ factor structure}

The results of the first estimate showed that the studied model achieved a satisfactory adjustment $(\mathrm{RMSEA}=.071, \mathrm{GFI}$ $=.948, \mathrm{AGFI}=.943, \mathrm{NFI}=.930, \mathrm{CFI}=.967, \mathrm{NNFI}=.965, \mathrm{x}^{2} /$ $\mathrm{gl}=2.93)$. However, the residual parameter was very high and statements with a low factor load, and incremental fit measures GFI, AGFI, NFI were lower than the ideal value $(>0.95)$, although acceptable $(>0.90)$.

The best adjustment $(\mathrm{RMSEA}=.062, \mathrm{GFI}=.963, \mathrm{AGFI}=$ $.958, \mathrm{NFI}=.949, \mathrm{CFI}=.981, \mathrm{NNFI}=.980, \mathrm{x}^{2} / \mathrm{gl}=2.48$ ) occurred: after increasing tolerance of the error covariance for the statements 20 and 23; 29 and 31, 32 and 12, 42 and 48; after the analysis of rates of change using the LISREL system; and after removal of the items 2, 5, 7, 17, 21,33, 35 and 37 due to low factor load and/or to high residue in the model.

Our analytical decision for accepting the covariance errors between items was based on LISREL's modification indices. Common reasons for this decision include item redundancy (caused by similar content or social desirability) and/or omission of an exogenous factor (Schumacker \& Lomax, 2004). Acceptance of a covariance error should be justified on theoretical grounds, rather than sole on statistical criterion (e.g., enhancement of a model adjustment; Silvia \& Maccallum, 1988). It is unlikely that social desirability is a factor associated to error covariance, since we ensured conditions for reducing bias (voluntary and anonymous participation) during data collection. It is also unlikely that a latent variable (factor) was ignored, since similar models were already proposed and investigated in previous studies. It is, therefore, possible that the existence of an error covariance was due to similar content between items, meaning that the participants perceived the content of the items to be similar.

Spearman correlation test allows us to confirm that statement 52 belongs to the $\mathrm{V}$ factor $(r h o=.422, p<.001)$, and that statements 24 (rho $=.470, p<.001), 25(r h o=.396, p<.001), 26$ $(r h o=.391, p<.001)$ and $27(r h o=.470, p<.001)$ belong to the BS factor. Finally, theoretical prediction of the original outlined study (Baxter et al., 2006) was confirmed for statement 51 (rho $=.401, p<.001)$ as part of the $\mathrm{T}$ factor, but failed to confirm that statement 53 ( $r h o=.226, p<.001)$ belonged to the $\mathrm{AC}$ factor. Table 1 summarizes the adjustment values of the scale (Table 1 ).

\section{Internal reliability}

Cronbach's alpha test and construction reliability values are presented in Table 2.

\section{Construct validity}

With regards the convergent validity factor, acceptable load
Table 2. Values of the reliability tests.

\begin{tabular}{c|cc}
\hline Factors & \multicolumn{2}{|c}{ Tests } \\
& Cronbach's Alpha * & Composite Reliability ** \\
\hline BS & $0.86 / 0.83$ & 0.82 \\
AC & 0.67 & 0.67 \\
BC & 0.83 & 0.76 \\
T & $0.77 / 0.80$ & 0.74 \\
V & $0.77 / 0.77$ & 0.82 \\
L & 0.72 & 0.76 \\
\hline
\end{tabular}

*Cronbach's alpha values placed on the left refer to the internal reliability factor calculated with the statements that comprise the factor for women in the Q group. For the BS factor, the statements are: 1, 3, 9, 12, 18, 19, $25,26,27,28,30,32$ and 40. For the V factor, the statements are: 4, 13, $15,22,39,41,42,48$ and 52 . For the $\mathrm{T}$ factor: the statements are: 29,31 , 34,46 and 50 . Values placed on the right refer to the internal reliability factor calculated with the statements that comprise the factor for the $\mathrm{M}$ group. For the factor BS, the statements are: 1, 3, 9, 12, 18, 19, 24, 30, 32 and 40. For the $\mathrm{V}$ factor, the statements are: 4, 13, 15, 22, 35, 39, 41, 42 and 48. For the T factor, the statements are: 29, 31, 34, 46, 50 and 51. ** Calculated only with statements common to all respondents.

Source: LISREL ${ }^{\circledR} 8.51$ e SPSS 15

factors were identified for items $4(\lambda \mathrm{i}=.451), 6(\lambda \mathrm{i}=.461), 13$ $(\lambda \mathrm{i}=.474), 38(\lambda \mathrm{i}=.479), 44(\lambda \mathrm{i}=.44)$ and $48(\lambda \mathrm{i}=.441)($ Hair Jr. et al., 2005). All other statements load factors included in the model exceeded .5, and all $t$-values exceeded 1.96.

The bivariate correlation Spearman test was used to assess relationship between sexual life satisfaction and the scores related to body stigma and the scores related to body concern factors. A negative correlation was found between sexual life satisfaction and both scores. Women who underwent a mastectomy without reconstruction showed significant correlation between satisfaction with sexual life and the scores of body stigma factor $(r=-.44, p$ $<.0001$ ), and women who underwent a mastectomy with reconstruction, or lumpectomy, or had no surgery exhibited significant correlation between satisfaction with sexual life and the scores of body stigma factor $(r=-.21, p<.0001)$. However, a negative correlation was found between satisfaction with sexual life and the scores of the body concern factor $(r=-.21, p<.0001)$.

With regard to discriminant validity, evidences suggest that the studied scale successfully discriminates the sampled women for changes in sexual life, and for different perceptions of financial security. There were statistical differences between scores of the body concern factor $(U=15176, p=.016, r=-.12)$, limitation $(U=14535.5, p=.003, r=-.15)$ and body stigma, both for women who had mastectomy with reconstruction, lumpectomy or had no surgery, and for those who underwent mastectomy without reconstruction $(U=14535.5, p=.003, r=-.18)$.

Considering the four levels of financial security perception (insecure, a little insecure, a little safe, and safe) for both women who had mastectomy without reconstruction, and for women who had mastectomy with reconstruction/lumpectomy /no surgery, financial security was statistically different for scores of all factors (Table 3). 
Table 3. Comparison of factor scores in relation to financial security.

\begin{tabular}{cccc}
\hline & $\boldsymbol{X}^{2}$ & $\boldsymbol{d} \boldsymbol{f}$ & $\boldsymbol{p}$ \\
\hline $\mathrm{T}(\mathrm{L})$ & 30.958 & & .000 \\
\hline $\mathrm{T}(\mathrm{M})$ & 9.665 & .022 \\
\hline $\mathrm{BS}(\mathrm{L})$ & 42.722 & .000 \\
\hline $\mathrm{BS}(\mathrm{M})$ & 13.019 & .005 \\
\hline $\mathrm{V}(\mathrm{L})$ & 36.583 & 3 & .000 \\
\hline $\mathrm{V}(\mathrm{M})$ & 14.658 & & .002 \\
\hline $\mathrm{L}$ & 82.491 & .000 \\
\hline $\mathrm{BC}$ & 53.531 & .000 \\
\hline $\mathrm{AC}$ & 48.237 & .000
\end{tabular}

$*(\mathrm{~L})=$ lumpectomy; $(\mathrm{M})=$ mastectomy

\section{Discussion}

The results of this study suggest that the Brazilian version of BIBCQ is a valid and reliable instrument to assess body image in women with breast cancer. The results confirmed the six factor model proposed by Baxter et al. (2006), including specific issues exhibited by women who underwent mastectomy without reconstruction, or lumpectomy, mastectomy with reconstruction or for those who did not perform any surgery.

The BIBCQ have adequate levels of internal consistency and construction validity. Our results suggest that the quality of sexual life is associated with some aspects of body image. Our results support the notion that active sexual life is a reflection of personal action and resources (such as resilience) which help to maintain a cohesive body identity (APA, 1994). As suggested by Hilton (1988), Stanton and Snider (1993), Lam and Fielding (2003), the financial security of women who survived breast cancer can be an important variable. The differences found between scores of groups with different perceptions of financial security also suggest that financial resources to purchase medication and hire professional assistance may have helped women during an early or a late recovery, making the structuring of identity after breast cancer an easier process.

The elimination of nine items of the original questionnaire could be due to translation problems. However, it seems unlikely, given the fact that an extremely careful process was performed to make sure the Brazilian BIBCQ version was equivalent to the original version in its idiomatic, semantic, cultural and conceptual terms, and to ensure that the version would be understood by the target population. It is more likely that cultural differences may have caused this situation. Some experiences with breast cancer are specific to Brazilian women. In this perspective, the removed items can be regarded as less relevant for analyzing the impact of breast cancer on body image of Brazilian women. In fact, other studies found differences in scales produced in other cultures when validated for Brazilians (Campana et al., 2009; Gouveia, Singelis, \& Coelho, 2002; Swami et al., 2011).

In general, the BIBCQ questionnaire could represent the insertion of findings for the Brazilian population in the international scenario of body image studies. Some studies have investigated the behavior towards cancer in people from different cultures such as, North Americans, Europeans, Australians, Japanese, Chinese, Koreans and Africans (Patel, 2013), but seldom with Brazilians. A questionnaire validation for the Brazilian people could enable cross-cultural research. It also could expand cross-cultural research on women's health and, more specifically, on breast cancer. Such instrument provides opportunities to identify the impact of various supporting programs on women, including immigrants in their efforts to improve or recover health. At a local level of public health programs for cancer, monitoring the impact of interventions on Brazilian women's health (BRASIL, 2006) allows more coherent adjustments in the medical treatment and psychological support. On a worldwide basis, identifying the strengths and weaknesses of Brazilian attitudes may allow health professionals to challenge unreasonable patterns of beliefs and expectations, by promoting new ideas and creating effective actions to improve women's health.

This questionnaire could also provide information about the differences between women who underwent breast reconstruction of women who did not lose either breast, and women who did not undergo reconstruction surgery. The questionnaire scales (vulnerability, body concerns, limitations, transparency, arm concerns and body stigma) can be used separately to evaluate a specific factor.

The BIBCQ questionnaire is an important tool for research in the health area and can be used by doctors, nurses, physiotherapists, physical educators and other professionals. Also, the BIBCQ questionnaire is an important tool to evaluate attitudes and perceptions towards the disease or its consequences (surgeries, collateral effects), to measure and follow the rehabilitation results related to body image or compare the effects of different kinds of exercise programs focused on body image (on a short or long term basis).

Nevertheless, a number of limitations must also be highlighted. This is the first psychometric study of BIBCQ in Brazilians, and it is limited to a non-probabilistic sample, so it does not represent the whole population. Future work in Brazilians and people from other cultures could offer a better understanding of body image in breast cancer survivors. Other psychometric properties such as, stability, time, predictive validity, and other evidence of construction validity should be investigated in future research. For developing countries, creating a reduced version of the scale would be interesting to ensure interviews with illiterate and operationally literate women. These women usually have limited access to health care, which make researchers' efforts to better understand them a priority. As a group of additional risk, unprivileged women who are survivors of breast cancer need specific actions to facilitate their process of identity reconstruction.

Despite these limitations, the study is a reliable scale and confirms its validity for assessing the impact of breast cancer on body image of Brazilian women.

\section{References}

American Psychological Association (1994). Diagnostic and statistical manual of Mental Disorders, Washington DC: Author. 
Annunziata, M.A., Giovannini, L., \& Muzzatti, B. (2012). Assessing the body image: relevance, application and instruments for oncological settings. Support Care Cancer, 20(5), 901-907. doi: 10.1007/ s00520-011-1339-x

Baron, R.H., Kelvin, J.F., Bookbinder, M., Cramer, L., Borgen, P.I., \& Thaler, H.T. (2000). Patients' sensations after breast-cancer surgery: a pilot study. Cancer Practice, 8(5), 215-222.

Baxter, N.N., Goodwin, P.J., Mcleod, R.S., Dion, R., Devins, G., \& Bombardier, C. (2006). Reliability and validity of the Body Image after Breast Cancer Questionnaire. The Breast Journal, 12 (3), 221-232.

Beaton, D., Bombardier, C., Guillemin, F., \& Ferraz, M.B. (2002). Recommendations for the Cross-Cultural adaptation of Healthy Status Measures. American Academy of Orthopaedic Surgeons Institute for Work \& Health, 1-34.

Brasil, Ministério da Saúde (2006). Protocolo de atenção à saúde da mulher. Principios e Diretrizes, Florianópolis, SC.

Campana, A.N.N.B., Tavares, M.C.G.C.F., Silva, D., \& Diogo, M.J.D. (2009). Translation and validation of Body Image Avoidance Questionnaire (BIAQ) to the Portuguese Language in Brazil. Behavior and Research Methods, 41(1), 236-243. doi:10.3758/ BRM.41.1.236

Cash, T.F. \& Pruzinsky, T. (2002). Body Image: a handbook of theory, research and clinical practice. The Guilford Press, New York, NY.

Dalton, E.J., Rasmussen, V.N., Classen, C.C., Grumann, M., Palesh, O.G., Zarcone, J., ... Spiegel, D. (2009). Sexual adjustment and body image scale (SABIS): a new measure for breast cancer patients. The Breast Journal, 15(3), 287-290.

Ferreira, L., Campana, A.N.N.B., Campana, M.B., \& Tavares, M.C. G.C.F. (2011). Descrição de duas alterações feitas ao protocolo da "American Academy of Orthopaedic Surgeons Institute for Work and Health" para adaptação cultural de escalas. VIII Congresso Iberoamericano de Avaliação/Evaluación Psicológica - V Conferência Internacional de Avaliação Psicológica: formas e contextos, Lisboa.

Garver, M.S. \& Mentzer J.T. (1999). Logistics research methods: Employing structural equation modeling to test for construct validity. Journal of Business Logistics, 20(1), 33-57.

Gouveia, V.V., Singelis, T.M., \& Coelho, J.A. (2002). Escala de Auto-Imagem: Comprovação da Sua Estrutura Fatorial. Avaliação Psicológica, 1,49-59.

Hair, J.F., Anderson, R.E., Tatham, R.L., \& Black, W.C. (2005). Análise Multivariada de Dados. 5ed. Bookman, Porto Alegre.

Hilton, B.A. (1988). The Phenomenon of Uncertainty in Women with Breast Cancer. Issues in Mental Health Nursing, 9(3), 217 - 238.

Hopwood, P., Fletcher, I., Lee, A., \& Al Ghazal, S. (2001). A body image scale for use with cancer patients. European Journal of Cancer, 37(2), 189-197.

Hormes J.M., Lytle, L.A., Gross, C.R., Ahmed, R.L., Troxel, A.B., \& Scmitz, K.H. (2008). The Body Image and Relationships Scale: Development and Validation of a Measure of Body Image in Female Breast Cancer Survivors. Journal of Clinical Oncology, 26(8), 1269-1274. doi: 10.1200/JCO.2007.14.2661

Hu, L. \& Bentler, P.M. (1999). Cutoff criteria for fit indexes in covariance structure analysis: Conventional criteria versus new alternatives. Structural Equation Modeling: a Multidisciplinary Journal, 6(1), 1-55. doi:10.1080/10705519909540118

Instituto Nacional de Câncer José Alencar Gomes da Silva (INCA) (2011). Estimativa 2012: incidência de câncer no Brasil. Inca, Rio de Janeiro. Retrieved from http://www.inca.gov.br/estimativa/2012

Lam, W.W.T. \& Fielding, R. (2003). The evolving experience of illness for Chinese women with breast cancer: a qualitative study. Psycho -Oncology, 12(2), 127-140. doi: 10.1002/pon.621
Luskin B.D., Warner, A.M., \& Knapik, G.P. (2006). Body Image. In: Morof Lubkin, I. \& Larsen, P.D. (Eds.). Chronic Illness: impact and interventions (pp. 181-197). Sudbury: Jones \& Bartlett.

Maruyama, G.M. (1998). Basics of structural equation modeling. London: Sage Publications.

Nunnally, J.C. (1978). Psychometric theory (2 ${ }^{\text {nd }}$ ed.). New York: McGraw-Hill.

Patel, G. (2013). The psychosocial impact of breast cancer diagnosis and treatment in Black and South Asian women. $\mathrm{PhD}$, University of the West of England.

Preston, M.M. (2010). An Exploration of Appearance-Related Issues of Breast Cancer Treatment on Sense of Self, Self-Esteem, and Social Functioning in Women with Breast Cancer. Doctorate in Social Work. University of Pennsylvania.

Schumacker, R.E. \& Lomax, R.G. (2004). A beginner's guide to structural equation modeling. 2nd edition. Hillsdale, NJ: Erlbaum.

Silvia, E.S.M. \& Maccallum, R. C. (1988). Some Factors Affecting the Success of Specification Searches in Covariance Structure Modeling. Multivariate Behavioral Research, 23, (3), 297-326.

Stanton, A.L. \& Snider, P.R. (1993). Coping with a breast cancer diagnosis: A prospective study. Health Psychology, 12(1), 16-23. doi: 10.1037/0278-6133.12.1.16

Swami, V., Campana, A.N.N.B.C, Ferreira, L., Barrett, S., Harris, A.S., \& Tavares, M.C.G.C.F. (2011). The Acceptance of Cosmetic Surgery Scale: Initial examination of its factor structure and correlates among Brazilian adults. Body Image, 8(2), 179-185. doi: 10.1016/j. bodyim.2011.01.001

Vamos, M. (1993). Body Image in chronic illness: a reconceptualization. International Journal of Psychiatry in Medicine, 23(2), 163-178.

Venâncio, J.L. (2004). Atuação do psicólogo no câncer de mama. Revista Brasileira de Cancerologia, 50(1), 55-63.

White, C.A. (2000). Body Image Dimensions and Cancer: a Heuristic Cognitive Behavioral. Psycho-Oncology, 9, 183-192.

White, C.A. (2002). Body Images in Oncology. In: Cash, T.F. \& Pruzinsky, T. (Eds). Body image: a handbook of theory, research and clinical practice. New York: Guilford Press, pp. 379-386.

White, C.A. \& Hood, C. (2011). Body image issues in oncology. In: Cash, T. F. \& Smolak, L. (Eds). Body image: a handbook of science, practice, and prevention, $2^{\text {nd }}$ edition. New York: Guilford Press, pp. 333-341.

\section{Authors' note}

Carolina de Oliveira Gonçalves earned her masters' degree at the University of Campinas, Campinas, São Paulo, Brazil.

Maria da Consolação Gomes Cunha Fernandes Tavares and Angela Nogueira Neves Betanho Campana are with the Department of Adapted Physical Activity, University of Campinas, Campinas, São Paulo, Brazil.

César Cabello is with the Department of Obstetrics and Gynecology, University of Campinas, Campinas, São Paulo, Brazil.

\section{Corresponding author:}

Carolina de Oliveira Gonçalves

Av. Álvaro Otacílio, n. 3053, apt. 702. Ponta Verde 57035-180, Maceió, AL, Brazil

Phone: (55 82) 3377-2222

E-mail: cog2009@yahoo.com.br 


\section{Acknowledgments}

We are grateful for all women who kindly accepted to participate in this research. We thank the São Paulo Research Foundation (FAPESP) for the student fellowship during the master's program. We also thank the University of Campinas Hospital (CAISM-Unicamp) and other hospitals, clinics and NGOs that believed and supported our research. This study is part of a Master's thesis.

Manuscript received on March 23, 2013

Manuscript accepted on January 27, 2014

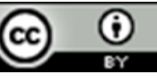

